\title{
LABOUR MARKET DYNAMICS FROM THE SURVEY OF FAMILY, INCOME AND EMPLOYMENT
}

\author{
Diane Ramsay \\ Statistics New Zealand, Wellington
}

\begin{abstract}
With the release of the first year's results from the longitudinal Survey of Family, Income and Employment Dynamics (SOFIE) in June and October 2004, Statistics New Zealand signalled the availability for the first time in New Zealand of dynamic data showing how an individual's circumstances change over time. This paper uses SOFIE information about spells of labour force involvement and participation in education or training to demonstrate the potential of dynamic data, to highlight the critical differences between SOFIE and Household Labour Force Survey data, and to point to the directions for future research as successive waves of SOFIE data are accumulated.
\end{abstract}

\section{Introduction}

At the end of October 2004, Statistics New Zealand released the results from the first year of interviewing in the Survey of Family, Income and Employment Dynamics. (SOFIE).

SOFIE is New Zealand's first-ever national survey designed to study individual, family and household income, how this income changes, and the factors that influence these changes such as involvement in the labour force or family composition.

SOFIE is a 'longitudinal' survey, which means that respondents will be revisited over a number of years to measure how their individual and family circumstances change over time. SOFIE differs from cross-sectional surveys that typically measure an individual's circumstances at the time of a single interview. Such surveys do not explain how the circumstances have arisen or changed over time, whereas results from SOFIE will show these changes. One analogy that may be used is that cross-sectional surveys provide a 'snapshot' at a point in time similar to a still photograph, whereas a longitudinal survey provides a more dynamic picture, similar to a video of a person's life.

As respondents to SOFIE are interviewed over time, a more complete picture of their lives will be able to be constructed, enabling the study of such questions as:

- Do people with low incomes continue to have low incomes?

- What is the pattern of income over time as people go through life?

- How do income levels for families and individuals change, and what are the factors that drive this change?

- What are the patterns of participation in the labour market over time?
- How do factors such as participation in education and training, and having children affect participation in the labour market and income levels?

- How long do people stay in the same job?

- How long do people spend looking for work?

SOFIE will provide a rich source of information about New Zealanders and their lives that will become richer over time. As the picture of an individual's circumstances builds up, more detailed analysis will be able to be undertaken.

The results released in October 2004 are from the first interview. As such the amount of longitudinal information is limited. However some transition information is possible by examining the changes from the beginning of the reference period to the end of the reference period. This paper looks at some of this early labour market transition data and illustrates what may be possible with SOFIE data as this dataset is enriched over time.

Statistics New Zealand produces information on employment and unemployment levels from the Household Labour Force Survey (HLFS) This survey also has a longitudinal nature, as attempts are made to interview respondents each quarter for eight quarters. Longitudinal analysis is possible from this survey as will be discussed in the following paper (Moore 2004). In this paper we seek to show that the collection of data on "spells" of labour market activity sheds further light on the measurement of labour market dynamics.

\section{SOFIE Methodology}

Between October 2002 and September 2003, approximately 11,500 households, selected from across the country, agreed to participate in SOFIE. All household members, including children, were selected and became our Original Sample Members (or OSMs). 
These individuals form the SOFIE longitudinal sample and will be interviewed each year for 8 years on their income, employment and family characteristics over the previous year. The final sample size for wave one is 22,000 adults and 8,000 children.

Respondents over 15 completed a "timeline" covering the previous year. This collects start and end dates of employment, family composition, and income. These periods of time are known as spells. Changes in employment and employment status, income, and family and living arrangements all triggered new spells.

Analysis of the spells reported over the year provides new data on the length of time and how often individuals experience particular states or conditions.

Note that the category "employed" includes those who are self employed, while the "not employed and not seeking work " category includes students, the retired and those with family or childcare responsibilities.

\section{HLFS Methodology}

The HLFS is a quarterly survey of approximately 15,000 households. Households remain in the survey for eight quarters before being rotated out of the sample and replaced by a new panel. Respondents are asked about their labour market activity in the reference week, that is the week before the interview takes place. Detailed information on labour market activity is collected in order to produce reliable estimates of the numbers of employed, unemployed and not in the labour force according to internationally comparable standards.

As no "spell" data is collected in the HLFS, no information about the circumstances of individuals between interviews is recorded.

It is important to note that the category in SOFIE, "not employed but seeking work" is not the same as the official measure of unemployment derived from the HLFS. This is because of the difficulty SOFIE respondents may have in remembering details of their job search activity and availability to start a new job over the year which are required for the HLFS measure.

\section{SOFIE Labour Market Dynamics}

\section{Changes In Labour Force Involvement Status}

Table 1 below shows the change in labour force involvement for all adults over the year. Most people have not changed their status, with $94 \%$ of people who were employed at the start of the period still reporting they were employed at the end of the year. However, $1 \%$ of these people were now not employed but seeking work while a further $5 \%$ of these were now not employed and not seeking work.

Of the 65,000 people who started the year not employed but seeking work, $52 \%$ remained in this state at the end of the year. However, $43 \%$ had become employed by the end of the year.

$87 \%$ of the people who said they were not employed and not seeking work at the beginning of the year remained in this state at the end of the year. However $12 \%$ of those not employed and not seeking work had become employed by the end of the year.

Like the HLFS data this analysis does not take into account the changes individuals have experienced during the year. For example some of the individuals who were still not employed but seeking work, may have had employment over the year. Further analysis of the spell data from SOFIE would be possible to examine this.

\section{Number and Duration of Labour Force Involvement Spells}

The collection of "spells" of labour force involvement enables us to look at both the length of time an individual has spent in various labour market states and the number of times they have been in this state over the year. This is not possible with the snapshot approach taken by the HLFS and other surveys.

Table 2 shows the duration of all spells (measured in weeks) of labour market involvement over the year. Table 3 shows the number of such spells. In these tables the sub-total row is for all individuals who experienced spells of this type, whereas the total row is for all adults

$68 \%$ of all people had employment spells over the year. Of these $78 \%$ were employed for the whole year and $94 \%$ had just one spell of employment. However $6 \%$ of people had 2 or more spells of employment over the year.

Of the 156,300 people who spent some time not working but seeking work $74,400(47 \%)$ spent less than 13 weeks in this state. However, $9 \%$ had two or more periods of this activity over the year.

$41 \%$ of all people spent time not employed and not seeking work over the year. Of those people who had spells of this type $67 \%$ spent 52 weeks in this state while $5 \%$ had two or more spells of this activity. 
Table 1: Change in Labour Force Involvement Status between Start and End of the Annual Period

\begin{tabular}{|c|c|c|c|c|}
\hline \multirow{2}{*}{$\begin{array}{l}\text { Labour force } \\
\text { involvement at start of } \\
\text { annual period }\end{array}$} & \multirow[b]{2}{*}{ Labour force involvement at end of annual period } & \multicolumn{3}{|c|}{ Total } \\
\hline & & \multicolumn{2}{|c|}{$(000)(1)$} & $\%$ \\
\hline \multirow[t]{5}{*}{ Employed } & Employed & $1,634.6$ & & 94 \\
\hline & Not employed but seeking work & 22.4 & & 1 \\
\hline & Not employed and not seeking work & 87.9 & & 5 \\
\hline & Overseas & .. & & .. \\
\hline & Total employed at start of annual period & $1,745.6$ & & 100 \\
\hline \multirow{5}{*}{$\begin{array}{l}\text { Not employed but seeking } \\
\text { work }\end{array}$} & Employed & 27.7 & & 43 \\
\hline & Not employed but seeking work & 33.5 & & 52 \\
\hline & Not employed and not seeking work & 3.9 & ${ }^{*}$ & 6 \\
\hline & Overseas &. & &.. \\
\hline & Total not employed but seeking work at start of annual period & 65.1 & & 100 \\
\hline \multirow{5}{*}{$\begin{array}{l}\text { Not employed and not } \\
\text { seeking work }\end{array}$} & Employed & 112.6 & & 12 \\
\hline & Not employed but seeking work & 12.5 & & 1 \\
\hline & Not employed and not seeking work & 830.9 & & 87 \\
\hline & Overseas & .. & &.. \\
\hline & Total not employed and not seeking work at start of annual period & 956.7 & & 100 \\
\hline \multirow[t]{5}{*}{ Overseas } & Employed & 23.7 & & 55 \\
\hline & Not employed but seeking work & 4.2 & * & 10 \\
\hline & Not employed and not seeking work & 13.9 & & 32 \\
\hline & Overseas & 1.6 & ** & 4 \\
\hline & Total overseas at start of annual period & 43.4 & & 100 \\
\hline \multirow[t]{5}{*}{ Under 15} & Employed & 7.2 & & 11 \\
\hline & Not employed but seeking work & 1.0 & ** & 2 \\
\hline & Not employed and not seeking work & 55.8 & & 85 \\
\hline & Under 15 & 2.0 & $* *$ & 3 \\
\hline & Total under 15 at start of annual period & 65.9 & & 100 \\
\hline Unknown & Unknown &.. & &.. \\
\hline \multicolumn{2}{|l|}{ Total } & $2,876.9$ & & 100 \\
\hline \multicolumn{5}{|c|}{ (1) Each count represents the individual's labour force involvement status for start and end spells in the annual period. } \\
\hline \multicolumn{5}{|c|}{$\begin{array}{l}\text { Symbols: } \\
\text { Estimates less than } 1,000 \text {. These have been suppressed for confidentiality reasons. } \\
\text { * A relative sampling error of greater than } 30 \% \text { and less than or equal to } 50 \% \text {; use data with caution. } \\
\text { ** A relative sampling error of greater than } 50 \% \text {; data is too unreliable for most practical purposes. }\end{array}$} \\
\hline
\end{tabular}


Table 2: Duration of Labour Force Involvement Spells

\begin{tabular}{|c|c|c|c|c|c|c|c|c|c|}
\hline \multirow{4}{*}{ Duration of spells (weeks) (1) } & \multicolumn{9}{|c|}{ Labour force involvement spells } \\
\hline & \multirow{2}{*}{\multicolumn{2}{|c|}{ Employed }} & \multirow{2}{*}{\multicolumn{2}{|c|}{$\begin{array}{l}\text { Not employed } \\
\text { but seeking } \\
\text { work }\end{array}$}} & \multirow{2}{*}{\multicolumn{2}{|c|}{$\begin{array}{l}\text { Not employed } \\
\text { and } \\
\text { not seeking } \\
\text { work }\end{array}$}} & \multirow{2}{*}{\multicolumn{3}{|c|}{ Overseas }} \\
\hline & & & & & & & & & \\
\hline & $(000)(2)$ & $\%$ & $(000)$ & $\%$ & $(000)$ & $\%$ & \multicolumn{2}{|c|}{$(000)$} & $\%$ \\
\hline Zero $^{(3)}$ & 909.4 & 32 & $2,720.6$ & 95 & $1,686.0$ & 59 & $2,822.9$ & & 98 \\
\hline Less than 13 weeks & 85.4 & 3 & 74.4 & 3 & 129.5 & 4 & 14.3 & & 0 \\
\hline 13 weeks to less than 26 weeks & 97.9 & 3 & 29.1 & 1 & 93.1 & 3 & 15.7 & & 0 \\
\hline 26 weeks to less than 39 weeks & 97.3 & 3 & 15.4 & 0 & 93.8 & 3 & 11.4 & * & 0 \\
\hline 39 weeks to less than 52 weeks & 137.3 & 5 & 10.3 & 0 & 81.5 & 3 & 11.6 & $*$ & 0 \\
\hline 52 weeks & $1,549.7$ & 54 & 27.2 & 1 & 793.0 & 28 & 1.1 & ** & 0 \\
\hline Sub Total (4) & $1,967.5$ & & 156.3 & & 1190.9 & & 54.1 & & \\
\hline Total & $2,876.9$ & 100 & $2,876.9$ & 100 & $2,876.9$ & 100 & $2,876.9$ & & 100 \\
\hline \multicolumn{10}{|c|}{$\begin{array}{l}\text { (1) Includes uncompleted spells. } \\
\text { (2) Counts are of individuals. } \\
\text { (3) No weeks spent in a labour force involvement spell of this type. } \\
\text { (4) Individuals who had a labour force involvement spell of this type. }\end{array}$} \\
\hline \multicolumn{10}{|c|}{$\begin{array}{l}\text { Symbols: } \\
\text { * A relative sampling error of greater than } 30 \% \text { and less than or equal to } 50 \% \text {; use data with caution. } \\
\text { ** A relative sampling error of greater than } 50 \% \text {; data is too unreliable for most practical purposes. }\end{array}$} \\
\hline
\end{tabular}

Table 3: Number of Labour Force Involvement Spells

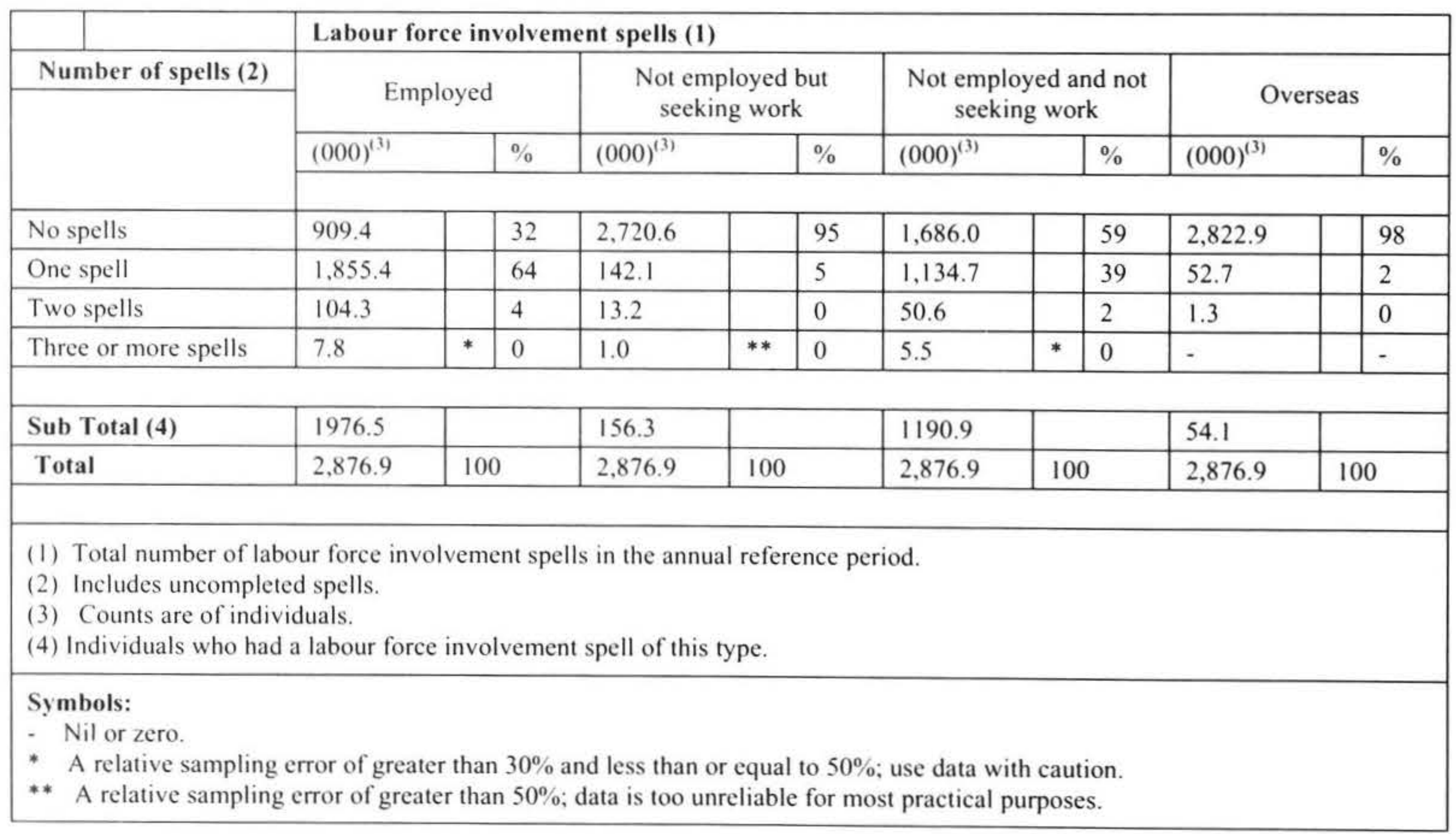


Income Quintile by Number and Duration of Weekly Employee Income Spells

Tables 4 and 5 look at the number of spells of weekly employee income by the distribution of this income.. This population is all those who over the year earned some income from employment. (Self employed are excluded.)

$16 \%$ of people who had weekly employee income, had spells of this income in the bottom quintile of the population (that is, less than $\$ 176$ per week). Of these, $18 \%$ had two or more spells of income at this level. However $35 \%$ spent less than 26 weeks at this level of income.

In contrast $24 \%$ of people with employee income had jobs that paid more than $\$ 887$ per week and of these $16 \%$ had two or more spells at this level.

Table 4: Income Quintiles by Number of Weekly Employee Income Spells

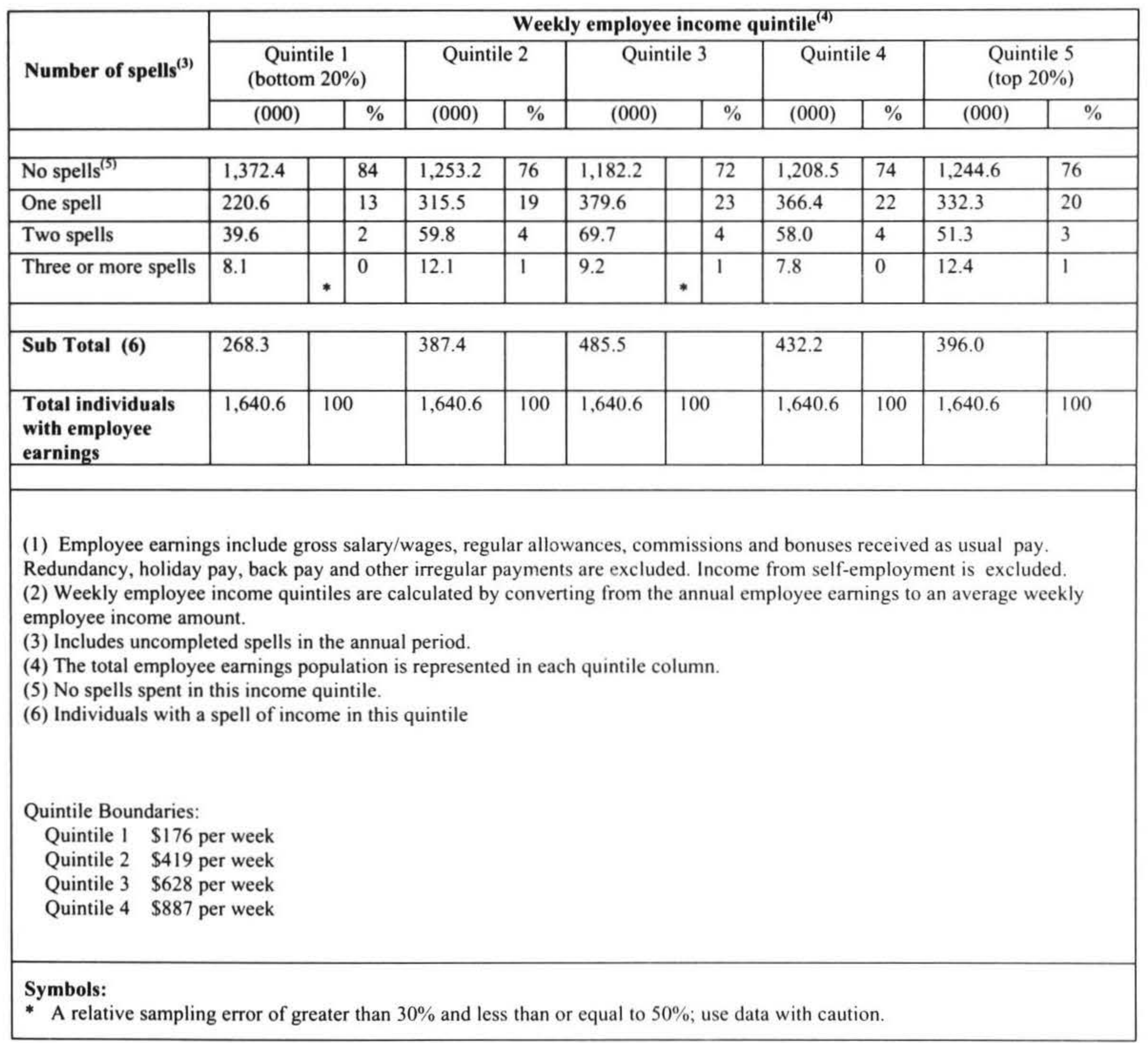


Table 5: Income Quintiles by Duration of Weekly Employee Income Spells

\begin{tabular}{|c|c|c|c|c|c|c|c|c|c|c|}
\hline \multirow{3}{*}{ Duration } & \multicolumn{10}{|c|}{ Weekly income quintile ${ }^{(2)(4)}$} \\
\hline & \multicolumn{2}{|c|}{$\begin{array}{c}\text { Quintile 1 } \\
\text { (bottom } 20 \% \text { ) }\end{array}$} & \multicolumn{2}{|c|}{ Quintile 2} & \multicolumn{2}{|c|}{ Quintile 3} & \multicolumn{2}{|c|}{ Quintile 4} & \multicolumn{2}{|c|}{$\begin{array}{l}\text { Quintile } 5 \\
\text { (top 20\%) }\end{array}$} \\
\hline & $(000)$ & $\%$ & $(000)$ & $\%$ & $(000)$ & $\%$ & $(000)$ & $\%$ & $(000)$ & $\%$ \\
\hline Zero $^{(5)}$ & $1,382.2$ & 84 & $1,261.2$ & 77 & $1,187.5$ & 72 & $1,214.2$ & 74 & $1,247.9$ & 76 \\
\hline Less than 13 weeks & 52.1 & 3 & 67.2 & 4 & 67.1 & 4 & 44.0 & 3 & 28.5 & 2 \\
\hline 13 weeks to less than 26 weeks & 39.3 & 2 & 65.0 & 4 & 61.9 & 4 & 44.4 & 3 & 24.0 & 2 \\
\hline 26 weeks to less than 39 weeks & 35.9 & 2 & 48.7 & 3 & 53.3 & 3 & 38.3 & 2 & 24.2 & 2 \\
\hline 39 weeks to less than 52 weeks & 26.7 & 2 & 44.4 & 3 & 50.8 & 3 & 42.9 & 3 & 25.2 & 2 \\
\hline 52 weeks & 104.5 & 6 & 154.1 & 9 & 220.0 & 13 & 256.7 & 16 & 290.7 & 18 \\
\hline Sub Total (6) & 268.3 & & 387.4 & & 485.5 & & 432.2 & & 396.0 & \\
\hline $\begin{array}{l}\text { Total individuals with employee } \\
\text { earnings }\end{array}$ & $1,640.6$ & 100 & $1,640.6$ & 100 & $1,640.6$ & 100 & $1,640.6$ & 100 & $1,640.6$ & 100 \\
\hline \multicolumn{11}{|c|}{$\begin{array}{l}\text { (1) Employee earnings include gross salary/wages, regular allowances, commissions an } \\
\text { Redundancy, holiday pay, back pay and other irregular payments are excluded. Income } \\
\text { (2) Weekly employee income quintiles are calculated by converting annual employee e } \\
\text { amount. } \\
\text { (3) Includes uncompleted spells in the annual period. } \\
\text { (4) The total employee income population is represented in each quintile column. } \\
\text { (5) No weeks spent in this income quintile by duration of employee earnings per week. } \\
\text { (6) Individuals with a spell of income in this quintile }\end{array}$} \\
\hline $\begin{array}{ll}\text { Quintile Boundaries: } \\
\text { Quintile 1 } & \$ 176 \text { per week } \\
\text { Quintile 2 } & \$ 419 \text { per week } \\
\text { Quintile 3 } & \$ 628 \text { per week } \\
\text { Quintile 4 } & \$ 887 \text { per week }\end{array}$ & & & & & & & & & & \\
\hline
\end{tabular}

\section{Conclusions}

This paper aimed to show that information on labour market dynamics could be produced from the first wave of SOFIE data that provides more information than current surveys. This information is derived from the "spell" data collected in the survey.

This data has shown that in general the amount of change experienced over a year is quite small. However the use of spell data enables us to examine both the length of time people experience various states and how often they move between states

This paper uses relatively simple techniques such as transition tables to show the dynamics. More sophisticated longitudinal analysis techniques such as survival analysis could also be used to further analyse this data.

The wave one SOFIE dataset contains a wealth of other data that could be analysed in conjunction with these basic labour market transitions. For example the impact of labour market transitions on family and household income, the reasons behind labour market change, involvement in study and other activities such as childcare.

As time goes on the SOFIE database will become richer enabling even more detailed analysis of the changes in individuals circumstances over time.

\section{References}

Statistics New Zealand. Reference Report Survey of Family, Income and Employment Dynamics. www.stats.govt.nz/sofie.

Moore T. (2004) Longitudinal analysis of labour force data. ibid 